\title{
DEVELOPMENT OF A METHOD FOR ESTIMATING MOTOR EFFICIENCY AND ANALYZING MOTOR CONDITION
}

\author{
J. D. Kueck \\ Oak Ridge National Laboratory
}

\begin{abstract}
There is a need for an efficiency estimating tool that can be used easily and with a reasonable level of confidence so that motors can be evaluated for replacement with energy efficient motors in a simple, cost-benefit analysis. In addition, it would be desirable to assess the condition of the motor at the same time the efficiency is being measured. This report provides an overview of various methods for estimating the operating efficiency of a motor without actually removing it from service and testing it on a dynamometer; the report also provides a concept for including a motor condition diagnostic into the same tool. The efficiency estimation and motor diagnostic tool needed for the cost-benefit analysis must be easy to use, without disrupting the operating process and must provide a reasonable accuracy.
\end{abstract}

The study reports on several efficiency estimation methods and compares them with actual dynamometer measurements of efficiency. It is found that reasonable estimates can be made without a high level of cost and disruption of the process. For example, if the motor can be disconnected from its load and operated at no load condition, and if a measurement of stator resistance may be taken, several of its losses can be reasonably approximated as in Method $E$ of the Institute of Electric and Electronic Engineers (IEEE) Standard 112 using a segregated loss method. This method can then be used when the motor is operated at its normal load condition to evaluate the losses in the motor and estimate motor operating efficiency. This method has been found to provide a reasonable estimate (perhaps 3 percent accuracy) when compared with the dynamometer method in the laboratory. However, disconnecting the motor from the load does require a short interruption in the process.

There are other less intrusive methods that use only measurements of input power and speed and then depend on empirical estimation factors. These methods have been found to have an accuracy of perhaps $4-5$ percent when used at loads above 50 percent load, but have a much larger error at low-load conditions.

Finally, there are new methods under development that provide a remarkably good estimation of efficiency with a minimal level of intrusion, but which, in their present implementation, require rather sophisticated data acquisition equipment and analysis software. One example of these is the air gap torque method where the voltage and current waveforms are acquired and analyzed to determine the power

\footnotetext{
- Prepared by the Oak Ridge National Laboratory, managed by Lockheed Martin Energy Research Corp. for the U.S. Department of Energy under contract number DE-AC05-96OR22464.

The submitted manuscript has been authored by a contractor of the U.S. Government under contract DE-AC05-96OR22464. Accordingly, the U.S Government retains a non-exclusive, royalty-free license to publish or reproduce the published form of this contribution, or allow others to do so, for U.S. Government purposes.
}

transferred across the air gap. If a lap top computer were equipped with the necessary software, voltage sensing leads, current transformers, etc., it would be possible to do two jobs at once - efficiency testing and motor condition analysis - with one set of measurements.

\section{INTRODUCTION}

Methods will be discussed for measuring the efficiency of motors already installed and operating. Testing in place results in several severe demands on the method of determining efficiency. Torque cannot be measured without installation of special instrumentation. It may not be possible to perform certain desired tests, such as no load tests, because of operational requirements. In some cases, the nameplate may no longer exist or may be unreadable. Even when the nameplate exists and is readable, the data may no longer be applicable because the motor has been reworked or rewound.

One of the key advantages of performing in-service testing is that factors such as voltage unbalance or harmonic distortion can be measured. While it is difficult to assess the exact effect of these factors on motor efficiency, the effect of these factors on motor rating can be easily estimated using guidelines in the National Electrical Manufacturers Association (NEMA) Standard MG1 [9]. Derating the replacement motor to account for these factors will significantly increase the motor lifetime and reliability and may well also improve efficiency.

At the same time data is acquired for an efficiency measurement, an analysis could also be performed to evaluate motor condition. A tool could be developed using a laptop computer in a briefcase. The computer would be loaded with software to perform both an air gap torque evaluation of the efficiency and an analysis of the motor's stator and rotor conditions.

\section{MOTOR LOSSES}

There are, in general, five components of motor losses, as follows:

Stator resistance losses $\left(\mathrm{W}_{1}\right)$ are the losses in the stator windings equal to $1.5 \cdot I^{2} \cdot R$ for a three-phase motor where $I$ is the average input line current and $R$ is the average $d c$ resistance between the line terminals.

Rotor resistance losses $\left(\mathrm{W}_{2}\right)$ are the losses in the rotor windings equal to $3 \cdot I_{2}{ }^{2} \cdot r_{2}$ for a three-phase motor where $I_{2}$ is the rotor phase current and $r_{2}$ is the rotor dc resistance. 


\section{DISCLAIMER}

This report was prepared as an account of work sponsored by an agency of the United States Government. Neither the United States Government nor any agency thereof, nor any of their employees, makes any warranty, express or implied, or assumes any legal liability or responsibility for the accuracy, completeness, or usefulness of any information, apparatus, product, or process disclosed, or represents that its use would not infringe privately owned rights. Reference herein to any specific commercial product, process, or service by trade name, trademark, manufacturer, or otherwise does not necessarily constitute or imply its endorsement, recommendation, or favoring by the United States Government or any agency thereof. The views and opinions of authors expressed herein do not necessarily state or reflect those of the United States Government or any agency thereof. 
Core losses $\left(\mathrm{W}_{\mathrm{h}}\right)$ constitute the hysteresis and eddy current losses in the iron. These losses vary approximately with the square of the input voltage, but for fixed input voltage these remain approximately constant from no load to full load. A common practice is to use no load measurements to estimate these losses.

Windage and friction losses $\left(W_{f}\right)$ are mechanical losses due to bearing friction and windage. These losses are also approximately constant from no load to full load. It is also a common practice to use no load measurements to estimate these losses.

Stray load losses $\left(\mathrm{W}_{\mathrm{LL}}\right)$ are the fundamental and highfrequency losses in the structure of the motor, circulating current losses in the stator winding, and harmonic losses in the rotor conductors under load. These losses are proportional to the square of the rotor current.

\section{DISCUSSION OF METHODS BY CATEGORY}

\section{A. Segregated Loss Methods}

The segregated loss methods are the most straightforward of the efficiency testing methods because they simply estimate the magnitudes of each motor power loss component. The individual loss components are then summed and subtracted from the power in to find the estimated power out. Some of the methods are quite complicated and intrusive, while others rely on empirical factors to estimate the losses.

\section{B. IEEE Standard 112-1996, Method E1}

Except in extraordinary circumstances, Method E is not a useful field test for efficiency. Its additional removed-rotor and reverse-rotation tests used to directly measure the fundamental frequency and high-frequency, stray-load losses are too invasive and user unfriendly. Therefore, attention will be restricted to Method E1. A literal interpretation of Method El would be impractical for field use, but the method is included here for completeness. Method E1, in its IEEE 112 format as discussed here, is probably seldom used in the field because it requires a variable load and a variable voltage power supply.

1. Method E1 specifies a comprehensive no load test.

2. Method E1 requires test under load at six equally spaced load points with four between 25 percent and 100 percent of full load and two greater than 100 percent and less than 150 percent.

3. Method E1 specifies an assumed value for stray load losses at rated load.

4. The repeatability of Method E1 is improved by requiring the adjustment of all resistance and slip measurements to a specified temperature.
Method E1 requires variable load tests, so the motor being tested must be connected to a variable load. Furthermore, during the no-load test the motor must be disconnected from its load and connected to a source of variable voltage. In most circumstances in the field this would be quite disruptive to normal operation of the system to which the motor is connected. Once the voltage, current, power, and RPM data has been collected, the algorithms provided in IEEE 112 are used to calculate the individual component losses.

\section{Ontario Hydro's Simplified Segregated Loss Method}

Ontario Hydro [1] proposes a segregated loss method that simplifies Method E1 much further. As pointed out in this study, it is not always possible to interrupt a process long enough to decouple a motor from, its load and conduct a noload test. The study suggests that one way around this obstacle is to assume a value for the combined windage, friction, and core losses. The study recommends that these combined losses be set to 3.5 percent of input rated power. The stray load losses are estimated based on the IEEE 112 standard assumed values.

This method can be simplified even further by using assumed values for rated power factor. Approximations can also be made for the temperature rise of the winding, and even the winding resistance could be estimated using a reading taken from the circuit breaker and subtracting the estimated cable resistance. The only other measurements required are power into the motor and motor speed. The author has experimented with a modified version of the Ontario Hydro method and found it to provide an accuracy of plus or minus 3 or 4 percentage points.

\section{Commercial Devices}

Commercial devices are available for measuring the efficiency of installed motors based on a modified version of the IEEE Standard 112, Method E1. These also require a measurement of power in, winding resistance, and speed.

\section{EQUIVALENT CIRCUIT METHODS}

The performance of an electric motor, at least with regard to efficiency, can be calculated from its equivalent electric circuit. These methods permit one to compute estimates of the efficiency of the motor when it is operating at loads other than those at which measurements were made.

\section{A. IEEE Standard 112-1996 Equivalent Circuit Methods}

The usual equivalent electric circuit of an induction motor is shown in the IEEE Standard 112-1996 [2], Method F.

Except in extraordinary circumstances, the IEEE Standard 112 Method $\mathrm{F}$ is not a useful field-test for efficiency. As is 
true for Method E, its additional removed-rotor and reverserotation tests to directly measure the fundamental frequency and high frequency stray load losses are too invasive and user unfriendly. Therefore, we will restrict our attention to Method F1.

The basic Method F1 requires an impedance test and the complete no-load, variable voltage test. The version of Method F1 believed more suited to field use requires volts, watts, amperes, slip, stator winding temperature, or stator winding resistance to be measured at two values of voltage while operating at no load. In one case, measurements are made at rated voltage while operating at no load. In the other case, measurements are made while operating at no load with voltage reduced until slip is equal to that obtained at the normal operating load. Once these measurements are made, an iterative procedure is used to determine the parameters of the equivalent circuit. The iterative procedure requires one to either know the design value of the ratio $X_{1} / X_{2}$ or to use the standard NEMA design value. Although this method is expected to be quite accurate, it is still considered to be too intrusive for routine field use.

\section{B. Ontario Hydro's Simplified Method F1}

A modified version of the IEEE Standard Method F1 [2] is outlined in the Ontario Hydro Study [1].

A no-load and a full-load test, both at rated voltage, must be run. In turn, this requires one to disconnect the motor being tested from its load. Line voltage, input power, line current, power factor, and stator resistance at load temperature is measured after operating at no load and at full load, i.e., the normal operating load of the motor. The slip is also measured at full load.

This method eliminates the need for a variable voltage as required by IEEE Standard 112, Method F1 [2].

The equivalent circuit used by this method is slightly different from that of Method F1. In this version of the equivalent circuit, the impedance elements of the magnetizing branch are shown in series while that of Method $F 1$ is shown in parallel. This simplifies the no load version of the equivalent circuit as shown in [1].

\section{Development of Equivalent Circuit from Nameplate Information}

The least intrusive method to estimate efficiency is based on the use of an equivalent circuit derived from the motor's nameplate data. Once the equivalent circuit of a motor is known, its running efficiency at any load can be determined simply by measurement of the motor speed.

The nameplate data provides information about the motor's rated performance, locked rotor current, and design type. Oak Ridge National Laboratory (ORNL) has developed a set of algorithms that find the equivalent circuit from this data plus the value of the stator resistance. If the stator resistance is not known, it can also be estimated from motor nameplate data. The algorithms incorporate refinements to the basic equivalent circuit to account for the skin factor effects on the rotor and to treat stray load and friction and windage losses explicitly.

The accuracy of this method is, of course, closely related to the accuracy of the data in the nameplate. When the skin effects and explicit losses refinements are used, the efficiency estimates are also affected by the accuracy of the selected factors. Even with typical nameplate information of older conventional motors and rewound motors, this method has been shown in limited testing to provide an average accuracy of less than 3.5 percentage points.

\section{Two Rotor Loops Equivalent Chfrcuit Methods}

The next two methods are based on an equivalent circuit that differs from the standard equivalent circuit. The revised equivalent circuit adds a second rotor loop.

\section{E. Locked Rotor Method}

A. Dell' Aquila, L. Salvator, and M. Savino [3] present a procedure that uses two locked rotor tests to determine the parameters of an equivalent circuit with two rotor loops. An alternative procedure is to use a single locked rotor in conjunction with a load test to determine these parameters. In both cases, a no -oad test must also be run. With these parameters in hand, they then develop a method for computing the efficiency of the motor from the equivalent circuit relationships.

The advantages of this two-rotor loop method are these areas:

1. The procedure for determining parameters of equivalent circuit is not iterative like that of Method F1.

2. According to the authors, the two-reactance loop equivalent circuit represents double-cage and deep-bar rotor motors better than the single rotor loop equivalent circuits.

This method has two principal disadvantages:

1. It requires a complete no-load test with the motor connected to a variable voltage power source.

2. It requires connecting the motor to a variable frequency source. This is too massive and user unfriendly for a good field test.

\section{F. Standstill Frequency Response}

A study [4] sponsored by the Electric Power Research Institute (EPRI) investigated the sensibility of determining 
the electrical equivalent circuit parameters of induction motors by using the standstill frequency response test. The approach investigated by the EPRI study was to measure the impedance of a motor, with its rotor stationary, over. a frequency range of 0.01 to $500 \mathrm{~Hz}$. The parameters of the equivalent circuit are then derived from these data.

The major advantage of this method over the standard Method F1 is that the low-voltage, no-load test is not required. The level of applied voltage is much lower than that of the low-voltage, no-load test.

If a packaged test device with a variable frequency source is developed and made commercially available, then the only drawback would be the no-load test to determine friction and windage.

\section{SLIP METHODS}

\section{A. Slip Method}

There are several versions of this method. All rely on a measurement of motor speed to find the slip. The measured slip (per unit) is the synchronous speed minus the measured speed divided by the synchronous speed. The rated slip is the synchronous speed minus the rated nameplate speed divided by the synchronous speed. The simplest version of the method is to find the ratio of the measured slip to rated slip and set this equal to efficiency. The obvious error is that the slip ratio represents the percentage of load and the efficiency is not equal to the percentage of load. Alternatively, one can also measure the power into the motor and approximate the power out of the motor by multiplying the rated horsepower of the motor by the ratio of the measured slip to rated slip. The operating efficiency of the motor is thus approximated using the following relationship:

\section{Efficiency $=$ \\ (Measured Slip/Rated Slip) $\times$ Rated Output Power Input Power}

Some users of this method try to enhance its accuracy by correcting the rated nameplate speed for voltage variations. This is done by taking the square of the ratio of the actual voltage to nameplate voltage and multiplying this times the rated speed. This is really only an exercise in good intentions, however, because the nameplate speed can be so inaccurate. The nameplate speed is allowed to deviate as much as 20 percent from the actual rated speed by NEMA MG1 [9].

The main attraction of the standard slip method is its simplicity. However, several authors, e.g., [2], [6], [7], and [1] have observed that the accuracy of the method suffers badly from several causes. Nailen [7] and the Arizona Department of Commerce Energy Office [5] provide an excellent discussion of the drawbacks of the slip methods, particularly the standard slip method. The scale of these inaccuracies is supported by the Arizona Department of Commerce Energy Office [2], which found that the slip method can differ from dynamometer results by over 40 percent.

\section{B. Current Method}

The current method is another approach that uses a minimum of field measurements in conjunction with manufacturer's data to estimate motor efficiency at normal operating loads. There are also several alternative current methods. Like the slip methods, the main attraction of the current method is its simplicity. Let $I_{r}$ be the rated current, $I_{m}$ be the measured current, and $I_{n 1}$ bot the no-load current. In its basic form, the current method estimates efficiencies as

$$
\text { Efficiency }=\frac{\left(1_{m}-1_{n 1}\right)\left(1_{r}-l_{n I}\right) \times \text { Rated Output Power }}{\text { Input Power }}
$$

This method requires a no-load test to obtain the no-load data. It also has a very serious drawback in that the current does not vary linearly with the load. This results in major inaccuracies, especially at low-load conditions. Reference 7 provides an excellent discussion of this problem and provides an improved version of the above equation, but concludes that even the improved version can have major inaccuracies depending on the shape of the motor performance curve and the load condition the motor is operating at.

Hsu et al. [6], and Nailen [7] summarize the advantages of the current method:

1. The NEMA Standard MG1-12.47 permits only half the tolerance in nameplate, full-load current as it does fullload slip.

2. Motor current measured by a clamp-on probe has a low intrusion level.

The chief disadvantage of the current method:

1. Current, unlike slip, does not vary linearly with load because there is a magnetizing current even when the motor is operating at no load. Therefore, this method also has a significant inherent inaccuracy.

\section{OTHER METHODS}

\section{A. Air Gap Torque Method}

Hsu and Scoggins [8] have proposed a new field method based on well-known air-gap equations for determining motor efficiency. The fundamental difference between the 
air-gap torque method and the methods using input power deductions, such as Method E1, is that the air-gap torque method considers the negative rotating torques caused by unbalance and by harmonics. It uses measurements of instantaneous input line voltages and line current and a set of integral equations to compute the average air gap torque. The authors' note that the data required by the method can be quickly obtained with an inexpensive personal computer system. Furthermore, this same computer can be programmed to quickly solve the air gap equations with numerical integration routines. Once the air gap torque is obtained, the efficiency is computed as follows:

$$
\begin{aligned}
& \text { Efficiency }= \\
& \frac{(\text { Air Gap }) \cdot 2 \pi\left(\frac{r p m}{60}\right)-W_{f+w}-W_{\text {core }}-\text { Stray load losses. }}{P_{i}}
\end{aligned}
$$

The advantages of the method:

1. Air-gap torque can be measured while the motor is running.

2. The air-gap torque method should continue to provide optimum accuracy when the phase powers are unbalanced.

3. This method can be used for non-induction motors such as the adjustable speed, brushless dc motors.

The major disadvantages of the method:

1. Current and voltage waveforms are required as input data.

2. Software required to analyze the field measurements.

\section{COMBINATION AIR GAP TORQUE METHOD AND CURRENT ANALYSIS TO DETERMINE MOTOR CONDITION}

The three basic electrical failure zones in induction motors are the stator, the rotor, and the core. The proposed method will accurately assess the condition of each of these three failure zones. In addition, the method will evaluate motor efficiency accurately. The motor is evaluated while it is running - the best time to assess its condition because of thermal and mechanical stresses that are present when it is running. The method is essentially a computer in a briefcase with leads for connection to the voltage terminals and clampon current transformers for acquiring current signals. Connections can be made at the circuit breaker. The computer will be equipped with data acquisition cards, voltage dropping circuitry, and the software for performing the motor on-line analysis.

The method requires a data acquisition system that can acquire the waveform data over a period of several seconds and software to perform the needed calculations. Both the data acquisition system and the software will be supplied in the computer

When the motor is operated at no-load condition, the airgap torque method can provide a measurement of the core losses as follows. The power transferred through the air gap to the rotor at no load is the sum of the rotor I squared $R$ loss and the friction and windage loss. The rotor I squared $R$ loss is nearly zero at no load. The friction and windage loss thus is essentially equal to the power transferred through the air gap that is calculated using the air-gap torque method. The power into the motor at no load is the sum of the friction and windage loss, core loss, stray load loss, and stator I squared $R$ losses. At no load, the stray load loss is essentially zero, and the stator I squared $\mathrm{R}$ loss can be determined by measuring the stator resistance and the statof current. The friction and windage loss is calculated; thus a measurement of the core loss can be made. This is as follows:

Power Into Motor is measured.

Friction and Windage is calculated using the Air-Gap Torque Method and assuming the Rotor I Squared R Loss is zero.

Stator I Squared R Loss is calculated using measured current and resistance.

Core Loss $=($ Power Into Motor $)-($ Friction and Windage $)-$ (Stator I Squared R Loss)

Also, since the friction and windage loss and the core loss are now determined, an accurate estimation of full load motor efficiency may be made, all with only a no-load test.

If a load test can also be made at some unknown level above 50 percent load, the method would use the air-gap torque method to make an extremely accurate assessment of motor efficiency at this load, within 1 percent, as noted above. This could be done in the field.

Rotor and stator condition may also be evaluated now using current analysis. When the motor is operating under load in the field, or at no-load condition in the shop, the voltage and current waveforms are loaded into the computer as above.

Once the voltage and current waveforms are loaded in the computer, digital filtering and demodulation of the waveforms are performed, and an FFT is performed. The $60 \mathrm{~Hz}$ component and harmonics of $60 \mathrm{~Hz}$ are eliminated. The components of the frequency domain are then examined to determine whether there is rotor or stator degradation.

The software may be written to allow the user to input whether he is performing a no-load or a load test. The software may be programmed to report each of the motor loss components, the motor efficiency vs. load curve, the 
condition of the rotor and stator, stator unbalance, and the overall core loss.

\section{SUMMARY}

In general, higher confidence levels are provided by the more intrusive methods. In most cases, the user is not trying to make an exact determination of efficiency, but only a reasonable efficiency estimate for the motor replacement decision making process. Thus, a high-confidence level estimate may not always be required.

The major shortcoming of all the in-service methods is that they are based, to varying levels, on approximations of the motor performance based on design information. Degradation in the motor, or losses to due improper rewinds, may well not be detected.

In addition to estimating the motor's load and operating efficiency, a significant advantage of making a field measurement is that the user will obtain data about the motors actual service condition, and conditions such as voltage phase unbalance, over or under voltage, or excessive harmonic distortion can be assessed and then properly addressed. A properly applied motor will, in general, be more efficient and more reliable.

A combination of the air-gap torque method and signature analysis of the acquired current waveforms has the potential to be a powerful diagnostic device.

\section{REFERENCES:}

[1] "In-Plant Electric Motor Loading and Efficiency Techniques," Ontario Hydro.

[2] "IEEE Standard Test Procedure for Polyphase Induction Motors and Generators," in IEEE Std. 112-1996, IEEE Power Engineering Society, May 8, 1997.

[3] Antonio Dell'Aquila, "A New Test Method for Determination of Induction Motor Efficiency," Technical Papers from the IEEE Power Engineering Society 1984 Winter Meeting.

[4] "Derivation of Induction Motor Models from Standstill Frequency Response Tests," GS-6250, Electric Power Research Institute, July 1991.

[5] Arizona Department of Commerce Energy Office, "Energy Efficient Motors for HVAC . Applications," April 4, 1994.

[6] J. S. Hsu et al., "Comparison of Induction Motor Field Efficiency Evaluation Methods," IEEE Transactions on Industry Applications, Vol. 34, No. 1, Jan./Feb. 1988.
[7] R. L. Nailen, "Finding True Power Output Isn't Easy," Electrical Apparatus, February 1994.

[8] J. S. Hsu, "Field Test of Motor Efficiency and Load Changes through Air-Gap Torque," Paper presented and distributed in the DOE's Tool and Protocol Workshop of Motor Challenge Program, September 22-23, 1994, Chicago, Illinois; accepted for publication, IEEE/PES Winter Meeting, January 27-February 2, 1995, New York, New York.

[9] National Electrical Manufacturer's Association (NEMA), NEMA Standards Publication Number MG1, 1993.

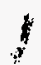




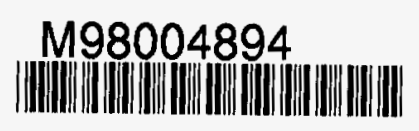

Report Number (14) ORNL/CP_-97271
CONF-980649-

Publ. Date (11) 199803

Sponsor Code (18) DOE, XF

UC Category (19) UC-900,DOE/ER 